\title{
Review of Cross-border Movements of Transnational Media Conglomerates
}

\author{
Jiarui Liu ${ }^{1, \mathrm{a}, *}, \dagger$, Xinlin $\mathrm{Liu}^{2, \mathrm{~b}, \dagger}$, Siyi $\mathrm{Tu}^{3, \mathrm{c}, \dagger}$, and Zimo $\mathrm{Xu}^{4, \mathrm{~d}, \dagger}$ \\ ${ }^{1}$ The University of Queensland, Brisbane, Queensland, St Lucia QLD 4072, Australia \\ ${ }^{2}$ University of Leeds, Leeds, West Yorkshire, LS2 9JT, United Kingdom \\ ${ }^{3}$ University of California, Santa Barbara, Santa Barbara, California, USA \\ ${ }^{4}$ Gezhi Senior High School of Shanghai China, Shanghai, China \\ "Corresponding author.Email: ${ }^{*}{ }^{*}$ jiarui.liu1@uqconnect.edu.au, ${ }^{b} f y 19 x 4 l @ l e e d s . a c . u k,{ }^{c}$ siyitu0604@163.com, \\ dx_zimo@163.com \\ These authors contributed equally.
}

\begin{abstract}
This review article tries to form a deep understanding of the effects of Transnational Media Conglomerates' (TNMCs') cross-border movements on cultural integration, exchange, or even some resistant practices in other foreign nations. Published books, journal papers, global business reviews, research articles, and other resources in relation to the crossborder movements of TNMCs will be used to support the analysis of this review article. Through reviewing those previous theoretical studies and particularly cross-cultural reception and effects of Hollywood film industry cases from cultural imperialism, cultural homogenization, and cultural globalization, we have found that the cross-border movements of TNMCs are complex and related to multiple factors included within the two most debated paradigms of global entertainment media - CI (cultural imperialism) and CG (cultural globalization). The combination of the above three cultural dimensions within the two paradigms found that the intensifying trends of globalization have promoted the integration of various cultures, leading to TNMCs better participation in the cross-border movements in the global entertainment market. Although there are many nations in the world system, global entertainment media industries, and culturally proximate markets, the US and US-based TNMCs still occupied the world's most dominant cultural primacy of TNMC production, distribution, exhibiting, marketing and consumption. However, the US Empire and its cultural imperialism are no longer necessarily adequate and effective enough to describe the global cultural condition through influencing other nations due to the transnational corporate culture developed from other nations' media organizations. Therefore, the cross-border movement of TNMCs would indeed cause the tension of local traditional culture and the trend of cultural homogenization to a certain extent. Still, different regions have different attitudes and adjustment measures towards this crisis, and they are also trying to export their values and profit from it at the same time. This article can provide a clear framework for future researchers to understand the balance of local and invading cultures and the future development of TNMCs. However, there are limited sources about other non-US TNMCs, so this review article may not provide a complete analysis of the overall TNMCs.
\end{abstract}

Keywords: Transnational Media Conglomerates (TNMCs), US-based TNMCs (Hollywood), Cultural Imperialism, Cultural Homogenization, Cultural Globalization.

\section{INTRODUCTION}

In the global entertainment industry, globalization occurs when domestic media firms reach beyond their national borders to engage audiences and consumers in other countries. Under the intensifying trends of globalization, the power of this kind of cross-border movement from transnational media conglomerates represents that soft power has extended to be equally significant into the cultural dimension.

Transnational media corporations (TNMCs) are the most structurally powerful media entities within the world system, and the dominant position of the world system's hierarchy is occupied by the US and the top USbased TNMCs such as Walt Disney, Time Warner, Comcast-NBC-Universal, News Corporation, Viacom, 
and CBS Corporation. As what has been demonstrated by Schiller, the first US communication studies scholar who focuses on researching and conceptualizing how American Empire has ideologically promoted its expansion through cultural imperialism within global entertainment media studies. TNMCs were risen from the end of the Cold War to describe the transformation of once exclusively American media corporations merged and converged with non-U.S. firms [1]. Under the organization of a global network that includes multimedia corporations, TNMCs are nationally-based but produce and distribute national and globalized entertainment media and operate a diversified business that expands to subsidiary corporations to reach both mass and niche audiences in many different countries $[1,2]$.

The global entertainment media is sourced by the TNMCs, especially the US-based first-tier TNMCs who have cultural primacy in the global audio-visual markets. The most influential rival theoretical or paradigms in the study of global entertainment media-cultural imperialism (CI) and cultural globalization (CG) were used by numerous scholars to examine and describe the processes and effects in relation to the cross-border movements of TNMCs within the context of television shows and films.

Through reviewed the various literatures, we find that the cross-border movements of TNMCs are not unidirectional. While it expands outward to spread cultural imperialism and cultural heritage, it is also constantly carrying out cultural exchanges and cultural fusion. However, most of the current literature is limited to specific research in the Asian region and short-term surveys. The scope of research does not fully cover all large-scale TNMCs, so there are still certain limitations and biases in the summarized results [3-8].

Although the CI paradigm is moving towards the newer $\mathrm{CG}$ paradigm under the current globalization trends, the two contested paradigms that were emerged and emphasized in different periods still significantly shape the contemporary world. Therefore, based on these two contested paradigms, our literature review will take the neutralized position. We aim to examine whether the cross-border movements of TNMCs lead to the deepening of cultural imperialism or cultural globalization, or the situations are more complicated through researching the localized case studies in specific countries. To achieve this objective, this literature review's main body is divided into three cultural dimensions derived from the two paradigms, which are cultural imperialism, cultural homogenization, and cultural globalization (cultural exchange \& cultural diversity). These concepts discuss CI and CG's paradigm from a holistic perspective and individual case analysis respectively. The first part elaborates on how the notion of cultural imperialism has been affected to develop dynamically and demonstrate whether US-based TNMCs are agents of cultural imperialism through predominately refines cultural imperialism by examining globally popular entertainment forms, blockbuster event films, and the expansion of TNMCs under the theoretical framework of New International Division of Cultural Labor (NICL). The second part mainly analyzes the relationship between the development of TNMCs and cultural homogenization. Further, it evaluates the degree of cultural homogeneity based on the impact of media penetration on cultural identities and industries in specific regions and understanding various countries' attitudes towards this trend. The third part mainly focuses on analyzing the inter-embedding relationship between various cultural elements and Hollywood films elements in several regions and countries' entertainment movie industries across different periods. Further, it demonstrates how this US-based TNMCs ("Hollywood") affected and created cultural diversity through reciprocating cultural exchange under the globalization trend.

Through this systematic review, we intend to understand how the cross-border movements of TNMCs (especially US-based TNMCs) have affected cultural integration, exchange or even resistant practices in other nation-states. The value of this review article is to increase the understanding of the balance between local culture and invading culture and to further contribute to the debate among CI and CG paradigms which would inspire the scholars to understand the positioning and influence of TNMCs and thus inspired them to make full preparations for future cross-media flow.

\section{CULTURAL IMPERIALISM}

Cultural imperialism represents and sources the cross-border movement of entertainment media ("TNMCs") and accounts for disseminating global films and TV shows within the world system. The first key area of this subsection vertically demonstrated cultural imperialism from its origin to how it has been affected dynamically due to the emergence of TNMCs from a holistic perspective.

In 1971, Herbert Schiller published the Mass communication and American empire, which is the original sourcebook associated with the theory of cultural imperialism. Then, in his most influential and heavily cited monograph related to cultural imperialism, the Communication and Cultural Domination, he conceptualized cultural imperialism as tools of Americanization and a new form of the US empire's expansive project. It accompanies globalization and modified to masterfully synthesize his cultural imperialism theory as a model of "basic relationships that structure power domestically and internationally" [2, 9]. As Schiller carried out his research further, he began to notice the rising importance of transnational media 
corporations (TNMCs), which stimulated him to focus on studying how the growing power of TNMCs has shaped and colonized the US from a cultural dimension and arguing cultural imperialism has become "transnationalized" in comparison with a distinctively "Americanized" one it once was [10,11].

Through reviewed several pieces of literature, it can be found that the dynamic notion of cultural imperialism has been subject to continuous critical reviews, debate, and revitalization over an extended period under the intensifying trends of globalization. In particular, this notion is undertaking an analysis of the ownership, production, distribution, marketing, exhibition and consumption of transnational films and television shows from political economy and cultural studies $[1,12,13]$. By developing a neutralized perspective from cultural imperialism and cultural globalization, Mirrlees focuses on examining the cross-cultural reception and effects of TV shows and films among US-based TNMCs, including non-US media corporations, states, and cultures. On the contrary, Grainge is pointing to the need for studying the complexities of TNMCs cultural production rather than use and reception $[1,12]$.

Throughout these pieces of literature, consistent evidence can be found to support the very valid point illustrated by Schiller that TNMCs supported the persuasive expansion of the US empire, but take into consideration national cultural specificities, and thus frequently adopted a not explicitly Americanized approach than they used to do during the Cold War $[1,10,11,12,13,14]$.

This valid point calls attention to the fact noticed by TNMCs, that "manufacture and export of overtly 'Americanized' films and TV shows to countries around the world is not a solid business strategy". Therefore, they intend to gradually de-Americanize their entertainment and media productions by designing global blockbusters, global-national TV formats, and trans-local lifestyle brands. By doing so, it has been more illustrative that the cultural imperialism scholars correctly argue the overarching goal of TNMCs, which is to expand their market dominance more effectively [1].

To examine whether TNMCs are agents of cultural imperialism, the second key area of this subsection focuses on reviewing the most influential US-based TNMCs, Hollywood, including its engineering of blockbuster films and New International Division of Cultural Labor (NICL).

Three key studies offered an insightful way to discuss the power relationships within the Hollywood industry (US-based TNMCs) and how 'Hollywood blockbuster films' are used to downplay the perceivable "Americanization" (cultural imperialism) to eventually reverberate cross border and profiting $[1,12,13]$. Mirrlees found that not all Hollywood blockbuster films are agents of cultural imperialism, while Miller et al. demonstrate that due to Hollywood "blockbuster" work simultaneously with Hollywood's domination over the major marketing corporations and the exceptional expenditure on promotion, the majority of countries and independent filmmakers were kept from accessing or accomplishing in the globalized film market $[1,13]$. In addition to these two studies, Grainge considered Hollywood blockbuster films as branding strategies without stopping at earlier debates surrounding cultural imperialism [12]. He argued that to guarantee steady profits, branding practices have been taken up in the entertainment media industries, particularly the Hollywood film industry, and have constructed films as huge media events (blockbuster) situated within transnational marketing under globalized TNMCs [12].

The key understanding drawn from these studies is that through globalized commodity content and form, TNMCs distinguish their persuasive merchandising to further segment different nations into niche and lifestyle markets.

In seeking a more comprehensive understanding of the dominant US-based TNMCs, the New International Division of Cultural Labor (NICL) concept was deployed to examine how they integrate and contend their authority over the cultural labor market through effectively do away with international boundaries [1]. Hollywood's cultural imperialism was refined by introducing the concept of NICL as the theoretical framework $[1,13]$. The NICL directly accelerate businesses to expand transnationally to include the global workforce as part of the commodity chain and competing among themselves. This can be evidenced by Mirrlees's argument that "the NICL is coordinated by many nations, not just one powerful US state that aggressively pushes the trade interests of its own media corporations in weaker countries" $[1,14]$. However, through argued for a more sophisticated system that functions to establish the NICL, the General Agreement on Tariffs and Trade (GATT) and the World Trade Organization (WTO) were explored and affirmed to be the significant reasons that were leading up to Hollywood's control over the NICL, which increases its cultural imperialism [13]. Therefore, Miller et al. concluded that depending on the exploitation of cultural labors within the NICL, Hollywood's global success comes from its control of the NICL [13].

In general, within the context of cultural imperialism's commodity form, the entertainment production of films produced by the US-based TNMCs are compatible with transnational and sub-national commodity forms to promote cultural homogeneity through exporting the American way of wife transnationally. Cultural imperialism may be a fact in some contexts. However, as Schiller observed: "American cultural imperialism is not dead, but it no longer adequately describes the global cultural condition" 
because "transnational corporate culture" is now "the central force, with a continuing heavy flavor of US media know-how, derived from long experience with marketing and entertainment skills and practices" [10].

\section{CULTURAL HOMOGENIZATION}

While the media provides connections between society and culture, it is sometimes seen as part of a broader social change process that weakens collective differences [15]. With the rise of the concept of globalization in the 20th century, culture continued to develop through the superficial cross-border communication of mass media, and liberal pluralists began to recognize the rise of TNMCs and the decline of nation-states as the main actors [16]. Since then, cultural imperialism has become a hot topic. Under such hegemonic penetration, individual culture has been eroded, and the spread of cultural forms has gradually become standardized. The resulting cultural homogenization has aroused great controversy in academia [15]. Scholars have begun to carry out various researches in the area of cultural homogeneity caused by the cross-border movement of TNMCs.

Szalvai, Kamp, and Branston et al. concluded that based on the unequal relationship between power and economy, the transnational cultural flow had provided more and more third-party countries with standardized media content, creation, and distribution that could affect their own culture so that the traditional local culture was destroyed by the external pressure of stronger countries, which invisibly strengthened the homogeneity of culture worldwide [17-19]. However, looking at the entire process of globalization from the perspective of the expansion of TNMCs, the emergence of cultural imperialism and the formation of homogenization of cultural products was obviously too singular. Their studies have also fully considered all aspects, indicating that the dominant cultural field played a role in shaping cultural flow. When different cultural dimensions tried to overcome and weaken each other, these different dimensions would also shape each other in dialectical communication [17-19]. These authors argued that the view of absolute cultural homogeneity ignored this interaction and the process of receiving cultural products [17-19]. Although the dominant culture was distributed in various places through the cross-border communication of TNMCs, the audience's consumption and understanding of it were not the same [17-19]. Different cultures and orientations would merge in this process [17-19]. On this basis, Szalvai has derived a new viewpoint about interlocolization [18]. The emergence of this concept further demonstrated the complexity of cultural communication caused by TNMCs. With the process of oppression and homogenization of a vertical hegemonic culture, cultural products with a high degree of distinctiveness also flowed and mixed horizontally and locally, forming a new cultural and political structure
[18]. Judging from the above literatures, while the globalization of the TNMCs has caused cultural homogeneity, it also inevitably embodies the diversity of hybrid cultures.

However, all of the above is from a holistic perspective. There is no specific and more convincing example to further demonstrate the degree of cultural homogeneity in the globalization movement of TNMCs. Therefore, some studies have begun to study the specific impact of the specific company or specific area. Some critics usually define the origin of cultural homogeneity and cultural imperialism as the West, especially the conscious and organized efforts made by American giant communication groups to maintain commercial, political, and military advantages [20]. These TNMCs exert their power through extensive expansion in cultural control and governance, thus saturating most countries' cultural space in the world [20]. Among them, one of the most famous TNMCs is Hollywood studios. With the process of globalization, Hollywood continues to acquire and expand, and its culture is also promoted and penetrated on a large scale.

$\mathrm{Su}$ and Klein respectively discussed the losses and opportunities brought about by the import of Hollywood blockbusters to Chinese and Asian cultures and the local government's attitude and countermeasures to this $[3,4]$. Among their research, some radical parties argued that whether it was for China or Asia, the transnational penetration and invasion of the Hollywood industry would cause people to lose their identity and make cultures become more and more closely integrated to a certain extent $[3,4]$. Except for the viewpoints held by a small number of people mentioned above, the results of these two studies both had a positive attitude towards the emergence and development of homogenization $[3,4]$. Su believed that China's debate on cultural homogenization from Hollywood's transnational communication was actually a reference for the Chinese people to understand their own modernization process and national identity [3]. Klein also stated that Hollywoodization and Asianization, globalization and localization, homogeneity and heterogeneity could go hand in hand to a certain extent [4]. For example, the origins of martial arts movies were deeply rooted in specific cultural traditions and spread smoothly [4]. They adapted to new conditions and had new meanings without losing all contact with their origins [4]. As a result, it could be seen that various countries and regions have their own dialectic views to the trend of cultural homogeneity. As for the cross-border expansion of the TNMCs, various regions also make different efforts and benefit from it. In addition to the above researches, more studies about the impact of Hollywood blockbusters on third-world parties will be illustrated in the next section, emphasizing cultural exchanges and diversity. 
Generally speaking, no matter from the perspective of the whole or the specific case studies, the cross-border movement of TNMCs is very complicated, and it cannot be explained by homogenization alone. Although a certain degree of cultural homogeneity will result in this process, different groups have different attitudes and coping methods in the face of it. When we realize that the invasion of transnational culture may threaten local culture, we cannot deny that culture also has a two-way flow pattern that cultural exchanges are happening at any time and cultural diversity is gradually increasing $[3,4,17,18,19]$.

\section{CULTURAL GLOBALIZATION}

Under the development of TNMCs and globalization trend, various cultures were exchanged and thrived through global entertainment industries. There are the cross-cultural effects of entertainment produced by TNMCs [1]. Transculturation can correlate to cultural imperialism and homogenization in cultural dominance, exploitation, and appropriation in media industries [21]. Furthermore, transculturation can be traced from cultural globalization and demonstrated with specific cultural exchange cases and diversity that happens through TNMCs in various countries and reflect the integration of diverse cultural elements from the world. The following paragraphs will review case studies of cultural exchange and diversity of Hollywood to explore the cross-border movements of TNMCs and their subsequent effects.

Cultural exchange is the reciprocal exchange of cultural symbols, ideas, traditions, and knowledge [21]. Cultural globalization has supported a great deal of crossborder cultural exchange, which can be seen from the exchange of American and other foreign cultures through the Hollywood movie industry. From researchers Maltby and Stokes's conclusions, specific effects of American films on different European, Asian, African countries and cultural contexts can be traced through the receptions of consumers from the 1910 s to the contemporary period [22]. People have adopted a lot of American concepts like gendered roles, the ideal of heroism, American accents [22]. Furthermore, both authors Wang and Ibbi have discovered that Hollywood TNMC has exerted a cultural influence in other foreign movie industries in China, India, and Nigeria [23,24]. The Hollywood cultural elements and techniques can be found in other indigenous movies in various countries $[23,24]$. US-based TNMCs have transmitted their own cultural content to others countries and formed the circulation of cross-border movements. It is clear to see the effects of Hollywood TNMC on different countries in different periods, from cultural imperialism to cultural globalization. American elements were exchanged to other countries, but foreign cultural elements were also learned in TNMCs industries, which has formed a two-way reciprocate interaction of cultural movements. From Chao, Matusitz, and Payano's studies, the phenomenon of Hollywood embracing and using the cultural elements from China and India can be learned $[5,6]$. This has demonstrated the current trend of cultural globalization and the flourish of diverse cultures through TNMCs' cross-border movements and effects.

With the example of the Hollywood industry, people can learn about the cultural exchange of American and foreign cultures from TNMCs worldwide. With cultural globalization and cross-border cultural movements, more and more cultures have appeared on the global entertainment stage and are known by global audiences. This has formed a broader way of cultural interaction and communication, which has led to the phenomenon of cultural diversity and demonstrated a greater integration of various cultures. As a result, with the free flow of ideas and enriched by constant exchanges and interactions between cultures, cultural diversity is strengthened and promoted [1].

Cultural diversity is how the meanings and symbols of culture are produced through complex processes of translation, negotiation, and enunciation [25]. Our study on cultural diversity mainly focuses on US-based TNMCs ("Hollywood") to understand how various cultures affected the Hollywood industry to create cultural diversity while showing the effects of Hollywood influencing different cultures from regions of the world. This study will be focusing on two perspectives: the mutual impact between various cultures and the Hollywood industry.

Cultural globalization in TNMCs enables numerous cultures to cooperate with America to create and strengthen cultural diversity in cultural globalization. Hollywood movie industries use many foreign cultural elements in their products and help them interpret and spread through a global scale $[7,8,26]$. Therefore, those cultures are benefited from the scenes, myths, or countercultures the movies used, and the people who shared the same culture will feel connected with the movie and the same experience of the culture. However, it is worth noting that this will also make people who are not familiar with the culture form a stiff impression $[7,8]$. As a result, we can find out that cultural diversity of multiple cultures from TNMCs can be found from Hollywood to be influencing other cultures and help to spread the countercultures shared by people. Yet, it may have side effects that those factors of cultures may be misled to a faulty stereotype.

Nevertheless, the Hollywood industry is also taking benefits from its collaboration with massive countercultures from other regions of the world to reinforce the effect of cultural diversity in TNMCs. We can see from different studies that the Hollywood movie industry is trying to work together with companies in Asia and learn from other popular movie forms to enlarge its audience group and expand its power towards the rest of the world [27,28,29]. Hollywood can benefit from those transactions they made with Asian cultures. They 
can mix the different ingredients of cultures into their movies to attract a wider range of audiences.

From the cultural exchange and diversity in TNMCs, we can see that various cultures are being exchanged and spread to all regions of the world. In contrast, cultural diversity is created and cultural globalization being strengthened through this process. American cultural elements are transported to the world, but they also helped other cultures be spread and shared by numerous regions of the world. Based on our systematic review, it is shown that cultural globalization in TNMCs can be caused by the process of cultural exchange and cultural diversity.

\section{CONCLUSION}

With the fast development and growing international position of TNMCs under the current advanced trend in the global market, the increasing influences of global entertainment industries pushing cross-border movements can be traced. Especially some US-based TNMCs like Hollywood and Disney have greatly affected the cultural propensity of entertainment industries and the development of other foreign media corporations and cultivated the global aesthetic tastes of audiences in various countries. Also, the integration of diverse cultures in these TNMCs under globalization can reflect two-way movements across countries. To deeply study this trend, this piece of article has analyzed three cultural perspectives - cultural imperialism, cultural homogenization, and cultural globalization by reviewing different academic sources.

The evidence of previous theoretical studies and USbased TNMC cases has helped us to conclude that Americanization's dominant forces in global entertainment industries have exerted cultural imperialism and cultural homogenization since the last century. Furthermore, with the complex contexts and updated periodically, the conditions of cross-border movements are complicated and have formed a transactional process to advance cultural flourish all over the world. We have found that under the global and interconnected media market which was created under the influences of TNMCs, not only American film elements were disseminated to foreign cultures, but also more cultures have entered the international stage and be recognized by more people, which has demonstrated the inter-dependent relationships between TNMCs and other cultures to form cultural globalization.

By analyzing these sources, we have found that the achievements and effects of TNMCs were not caused by a single factor. This is a very complex process that includes both cultural imperialism and cultural globalization and leads to a two-way cultural flow between national borders all over the world. This review article can provide a comprehensive analysis of TNMCs' current global position and development stage and outline the current global entertainment trend from the cultural perspective. Based on the above discussion, a clear systematic framework can be established for future researchers to understand the cross-border movements from cultural imperialism to cultural globalization as times go on. In addition, people can learn about the balance and relationship between local cultures and invading culture. Also, a future growing trend of the global entertainment and TNMCs can be predicted with the integration of cultural imperialism and globalization that more cultures may appear in the global industry and utilized by TNMCs to exert their great influences. However, this paper is mainly composed of US Hollywood TNMCs' cases, and there was not much about other large or foreign TNMCs, which limit the way to interpret the whole condition of TNMCs' cross-border movements. Future research can dive into analyzing more TNMCs' conditions and some European cases to form a more well-rounded study of TNMCs' global position and effects with the changes of the new era.

\section{REFERENCES}

[1] Mirrlees, T. (2013). Global entertainment media: Between cultural imperialism and cultural globalization. Routledge

[2] Schiller, H. I. (1976). Communication and cultural domination.

[3] Su, W. (2011). Resisting cultural imperialism, or welcoming cultural globalization? China's extensive debate on Hollywood cinema from 1994 to 2007. Asian Journal of Communication, 21(2), 186-201. https://doi.org/10.1080/01292986.2010.539301

[4] Klein, C. (2004) Martial arts and the globalization of US and Asian film industries. Comparative American Studies An International Journal, 2(3), 360-384.

[5] Chao, M. (2012). Traditional Chinese Elements Embedded in Hollywood Films. University of Wisconsin-Platteville.

[6] Matusitz, J., \& Payano, P. (2012). Globalisation Of Popular Culture: From Hollywood To Bollywood. South Asia Research, 32(2), 123-138.

[7] Gkritzali, A., Lampel, J., \& Wiertz, C. (2016). Blame it on Hollywood: The influence of films on Paris as product location. Journal of Business Research, 69(7), 2363-2370.

[8] Malik, S., Chapain, C., \& Comunian, R. (2017). Rethinking cultural diversity in the UK film sector: Practices in community filmmaking. Organization, 24(3), 308-329. https://doi.org/10.1177/1350508416689094 
[9] Schiller, H. I. (1971). Mass communications and American empire.

[10] Schiller, H. I. (1991). Culture, Inc: The corporate takeover of public expression. Oxford University Press on Demand.

[11] Schiller, H. I. (1992). Mass communications and American empire (2nd ed., updated.). Westview Press.

[12] Grainge, P. (2008). Brand Hollywood: selling entertainment in a global media age. Routledge.

[13] Miller, T., Govil, N., McMurria, J., Maxwell, R., \& Wang, T. (2019). Global hollywood 2. Bloomsbury Publishing.

[14] Mirrlees, T. (2016). US empire and communications today: Revisiting Herbert I. Schiller. The Political Economy of Communication, 3(2).

[15] Hodkinson, P. (2017). Media, culture and society. S.L.: Sage Publications.

[16] Thomas, A. O. (2001). Global Media Corporations and the Nation-state: Balancing Politico-economic and Socio-cultural Globalization. Global Business Review, 2(1), 71-82. doi:10.1177/097215090100200105

[17] Kamp, M.C. (2009). Where Corporate Culture and Local Markets Meet. Music and Film Majors in the Netherlands, 1990-2005. Rotterdam: Erasmus Universiteit Rotterdam.

[18] Szalvai, E. (2021). Emerging Forms of Globalization Dialectics: Interlocalization, a New Praxis of Power and Culture in Commercial Media and Development Communication. Retrieved 8 March 2021, from https://scholarworks.bgsu.edu/media_comm_diss/9 5/

[19] Branston, G., \& Stafford, R. (2010). The media student's book. Milton Park, Abingdon, Oxon: Routledge.

[20] Jin, D. Y. (2007). Reinterpretation of cultural imperialism: Emerging domestic market vs continuing US dominance. Media, Culture \& Society, 29(5), 753-771. doi:10.1177/0163443707080535

[21] Rogers, R. (2006). From Cultural Exchange to Transculturation: A Review and Reconceptualization of Cultural Appropriation. Communication Theory, 16(4), 474-503.

[22] Maltby, R., \& Stokes, M. (2004). Hollywood abroad : Audiences and cultural exchange. London: BFI Publishing.
[23] Wang, T. (2009). Understanding local reception of globalized cultural products in the context of the international cultural economy: A case study on the reception of Hero and Daggers in China. International Journal of Cultural Studies, 12(4), 299-318.

[24] Ibbi, A. (2013). Hollywood, the American image and the global film industry. Cinej, Iii(1), 93-106.

[25] Isar, Y. R. (2006). Cultural Diversity. Theory, Culture \& Society, 23(2-3), 372-375. https://doi.org/10.1177/0263276406023002153

[26] Glancy, H. M. (2014). Hollywood and the Americanization of Britain: From the 1920s to the Present. London: IB Tauris.

[27] Donovan, B. W. (2014). The Asian influence on Hollywood action films. McFarland.

[28] Kokas, A. (2017). Hollywood made in China. Univ of California Press.

[29] Marsha, E., \& Soedrajat, M. A. (2019). The Influence of China in Hollywood Environment. Contemporary Chinese Political Economy and Strategic Relations, 5(3), 1143-IX. 